Children's views on postsurgical pain in recovery units in Norway: A qualitative study

\begin{tabular}{|r|l|}
\hline Journal: & Journal of Clinical Nursing \\
\hline Manuscript ID & JCN-2018-0692.R2 \\
\hline Manuscript Type: & Original Article \\
\hline Keywords: & $\begin{array}{l}\text { Children, Pain, Experiences, Post Operative Pain, Pain Assessment, Pain } \\
\text { Relief, Interviews }\end{array}$ \\
\hline \multicolumn{2}{|l}{} \\
\hline
\end{tabular}

SCHOLARONE ${ }^{\text {m }}$

Manuscripts 


\title{
Children's views on postsurgical pain in recovery units in Norway: A qualitative study
}

\begin{abstract}
Aims and objectives: To explore children's postsurgical experiences with pain and pain management in the recovery unit.
\end{abstract}

Background: Children's pain is underestimated and undertreated. Untreated pain can cause unnecessary suffering, increased complication risks, and may lead to chronic pain. Research exploring children's experiences with postoperative pain and pain management is limited.

Design: A qualitative, exploratory study. The study complied with the Consolidated Criteria for Reporting Qualitative Research (COREQ).

Methods: Children $(\mathrm{N}=20), 8-16$ years old, took part in semi-structured interviews about their experiences with pain and postoperative pain management while they were in a recovery unit. Data were collected at two university hospitals in Norway. Content analysis was used to analyse the data. Results: Three themes emerged from the interviews; “children's experiences of what felt unpleasant and painful", "children's experiences with pain management" and "children's recommendations for future pain management". About half of the children reported moderate to severe pain while in the recovery unit and they did not always tell their nurses when they had pain. They also reported experiencing pain in places other than their surgical wounds and stated that nausea and vomiting felt unpleasant and painful. The children indicated that pain medications and the use of non-pharmacological methods helped them cope with their pain and provided several recommendations about how to improve pain management.

Conclusion: Paediatric postoperative pain management remains suboptimal. The children in our study provided useful information about their pain experiences, how to improve pain management and explained why they did not tell their nurses when they were in pain. 
Relevance to clinical practice: These findings should direct further improvements in paediatric postoperative pain management, such as increased use of pain assessment tools and preparatory information, as well as more appropriate administration of pain medications.

\section{KEYWORDS}

children, pain, experience, postoperative pain, pain assessment, pain management 


\section{INTRODUCTION}

Children's postoperative pain is underestimated and undertreated (Pope et al. 2017, Sng et al. 2017, Twycross et al. 2015). As a result, many children experience moderate to severe postoperative pain (Avian et al. 2016, Birnie et al. 2014, Kozlowski et al. 2014, Thienthong et al. 2014), which can cause unnecessary suffering and increase the risks of complications, morbidity, and mortality, as well as potentially leading to longer hospital stays (IASP 2017). A long-term consequence of inadequate relief from acute pain can be chronic postsurgical pain (CPSP), which is experienced by $10-20 \%$ of children undergoing surgery (Batoz et al. 2016, Rabbitts et al. 2017, Schug \& Bruce 2017).

The International Association for the Study of Pain (IASP) define Pain: “An unpleasant sensory and emotional experience associated with actual or potential tissue damage, or described in terms of such damage. Pain is always subjective". (International Association for the Study of Pain Task Force on 2018). This definition emphasizes the multidimensional aspect of pain. As pain is a biopsychosocial phenomenon it requires a multimodal approach to management (Twycross \& Williams 2014). One reason for suboptimal postoperative pain management may be the complexity of assessing pain in children (Mennella \& Heering 2017, Twycross \& Finley 2013). Many nurses believe that children over-report their pain (Ekim \& Ocakc1 2013, Ljusegren et al. 2012, Stanley \& Pollard 2013, Twycross \& Collis 2013) and thus use pain assessment tools inconsistently (Sng et al. 2013, Twycross \& Finley 2013) or use physical indicators of pain rather than the child's self-report to guide decision-making about appropriate treatments (Smyth et al. 2011). Further, nurses' beliefs and misconceptions (Twycross \& Collis 2013) or lack of knowledge (Ekim \& Ocakc1 2013, Ortiz et al. 2015, Smeland et al. 2018) about paediatric pain management may be barriers to effective pain relief. 


\section{BACKGROUND}

In recent years, children's perceptions of postoperative pain have been explored in studies from Canada (Birnie et al. 2014, Twycross \& Finley 2013), Thailand (Thienthong et al. 2014), Australia (Ford et al. 2012), Singapore (Sng et al. 2013), and Sweden (Rullander et al. 2013). These studies all support the notion that children continue to experience moderate to severe pain postoperatively. In the study by Rullander et al. (2013) several children also reported persistent pain 5-12 months after surgery. Children have described a range of negative emotions including anger, fear, and sadness in relation to their experiences with postoperative pain (Ford et al. 2012, Sng et al. 2013, Twycross \& Finley 2013). Of note, for some children, nausea is worse than pain (Rullander et al. 2013).

Children's views about their postoperative pain management have been explored in some studies (Ford et al. 2012, He et al. 2007, Sng et al. 2013, Twycross \& Finley 2013). Children have reported that pharmacological pain management is the most effective way to relieve their postoperative pain and indicated that it is important that nurses give them medications when they are needed (He et al. 2007, Sng et al. 2013). In relation to non-pharmacological methods, children have stated that the most important thing parents could do to help them cope with their pain was to be present (i.e. with them in the hospital) (He et al. 2007, Sng et al. 2013). Some children have reported receiving inadequate preoperative information about what to expect in the postoperative period (Ford et al. 2012, Twycross \& Finley 2013). Some children have also suggested that there is a need for improved communication between nurses and parents - so that parents have enough knowledge to deal with their child's pain (He et al. 2007). Children have also recommended the use of more non-pharmacological pain management techniques, such as distraction and positioning (Sng et al. 2013).

The aforementioned studies provide evidence that children's perspectives on experiences of postoperative pain can provide insight into the improvements needed for their postoperative pain management. However, very little is known about children's experiences about pain and pain 
management within the recovery units. Nurses working in recovery units have an important role in assessing and managing pain in children and so more knowledge is needed in these areas. This is the focus of this study.

\section{1 Aim}

The study aim was to explore children's experiences with pain and postoperative pain management in Norwegian recovery units. We also sought to gain insight into children's recommendations for nurses about strategies that could improve paediatric postoperative pain management, and what advice they would give other children undergoing surgery. With an overarching goal of influencing future clinical practice, we aimed to gain a greater understanding of children's experiences, and to gather their recommendations for improving postoperative pain management.

\section{METHODS}

\subsection{Study design}

This was a qualitative, exploratory study using semi-structured interviews of children after they had undergone surgery. This study focused on children's views, and was part of a larger study; Pediatric Pain Management - an Intervention Study, described at ClinicalTrials.gov (ClinicalTrials.gov Identifier: NCT03385681). The study complied with the Consolidated Criteria for Reporting Qualitative Research (COREQ) (See Supplementary File 1).

\subsection{Data collection}

\subsubsection{Sample}

We invited children six years or older who were undergoing elective or emergency surgery at two university hospitals in Norway to participate in the study. We excluded children with cognitive impairment who were unable to communicate verbally, those who did not speak Norwegian, and those who were admitted to the intensive care unit after surgery. All children who were interviewed 
were admitted to a recovery unit for both children and adults. Data were collected during October and November 2014.

\subsubsection{Data collection tools}

Two different semi-structured interview guides were developed: one for children aged 6-11 years; the other for those 12-18 years. The interview guides were based on work by Polkki et al. (2003) and by the Royal College of Nursing (2009), and included questions about what happened when they were in pain, if anyone asked if they were in pain, about what helped them when they were in pain and suggestions for nurses and other children who are undergoing surgery on how to manage pain. The interview guides were piloted on both age groups, after which a small adjustment was made, and an opening question added about why the child was hospitalized.

As part of the interview process, all children were also asked to rate the worst pain they had experienced during their stay at the recovery unit using a numerical rating scale (NRS) (von Baeyer et al. 2009) from 0 ("no pain") to 10 ("worst pain imaginable") or the Faces Pain Scale-Revised (FPS-R) (Hicks et al. 2001) depending on their cognitive abilities. Using the same scale, they were also asked to rate the worst pain experienced during their postoperative period and their current level of pain. Participants' age, gender, type of surgery, type of admission, and pharmacological treatments administered before, during, and after surgery (i.e. in the recovery unit) were recorded.

\subsubsection{Procedure}

The nurses on the surgical wards identified children who met the inclusion criteria and asked if they were interested in information about the study. The children and parents who accepted the invitation were given more information by a researcher and was then given time to consider whether they wished to participate. During the two weeks of recruitment, 26 children met the inclusion criteria and 20 were enrolled (Figure 1).

All but two children chose to have their parents present during the interview. The interviews were audio recorded and conducted after the children were discharged from the recovery units and 
before they were discharged from the hospital. Two researchers (LN and TN) conducted the faceto-face interviews, one interviewing and one observing. The one observing wrote down some field notes maintaining contextual details. Seventeen interviews were conducted within 48 hours after the child's surgery, and three took place between the third and fifth postoperative day. The interviews lasted 12-28 minutes and took place in a private room near by the recovery unit or on the surgical ward with only the interviewers and, if they chose, their parents present to ensure confidentiality and limit interruptions.

\subsection{Ethical considerations}

Ethical approval was obtained from the Regional Committee for Medical Research Ethics (REK South-East, Norway, id: 399805) and both hospitals' local Social Science Data Services (NSD) and unit managers. Children and their parents received verbal and written information about the study. Three different age-appropriate information letters were used: one for children 6-11 years; one for children 12-18 years; and one for parents. These letters included information about the study and explained that participation was voluntary and that their responses would be treated anonymously. The children were told that they could leave the study at any time without providing a reason and that doing so would not impact on the care they received. Furthermore, it was pointed out for the children that they could stop at any time during the interview if they needed a break, were in pain or did not want to continue. We obtained verbal informed consent from all children and written informed consent from all parents and children 12 years and older. The interviews were coded so that children could not be identified. Only the research team had access to the raw data, which were stored securely to ensure that confidentiality was maintained. The study was registered at ClinicalTrials.gov (ClinicalTrials.gov Identifier: NCT03385681).

\subsection{Data analysis}


The researcher who conducted the interviews also transcribed the children's responses verbatim using NVivo (QRS NVivo Pro for Windows, version 11). Content analysis was applied to the transcripts using a six-step approach (Creswell 2014):

1. Creating and organizing data files

2. Reading through the text and forming initial codes

3. Coding all data

4. Describing the social setting, people involved, and events

5. Analysing data to identify emerging themes

6. Interpreting and making sense of the findings

Three researchers (LN, TN and AHS) independently analysed the data and then thoroughly discussed the themes until consensus was achieved. Each researcher referred to the themes by slightly different names, although their content was similar.

\section{RESULTS}

Almost equal numbers of boys and girls aged 8-16 years participated. Their most common type of surgery was orthopaedic, and 16 of the 20 had undergone elective surgery. More than half of the children received intravenous opioids postoperatively. Background characteristics of the children are summarized in Table 1.

The three themes that emerged from the interview data will each be discussed in detail:

1. Children's experiences of what felt unpleasant and painful

2. Children's experiences with pain management

3. Children's recommendations for future pain management

\subsection{Children's experiences of what felt unpleasant and painful}

\subsubsection{My experience of pain in the recovery unit}


Half of the children reported experiencing moderate or severe pain while in the recovery unit (Table 2). For some children, their postoperative pain intensity escalated during their hospital stay. Children used a variety of words to describe their pain. Some described it in detail while others used short sentences; their descriptions included words such as sore, tender, bumping, aching, prickling, burning, unpleasant, and hurt.

One boy who had undergone emergency surgery and who had pain before the operationbut was not told it would hurt afterwards — described his experience:

Researcher (R): "Do you remember how you were doing when you woke up the first time after the surgery?”; Child (C): (whispering) "Then it was...so painful that I thought I was going to die." (Case 12, 11 years)

This child explained that his pain was nine out of 10 on the NRS when he awoke after surgery. He explained that his pain score on the NRS prior to surgery had been an eight and that the pain after surgery felt different. One child described how it felt having pain when she breathed:

$R$ : "Can you tell me how the pain felt, or is that difficult?"; C: "I almost have it when I breathe, but it feels a bit as if... as if everything stops up inside me...that it sort of...it's like you sort of...if you have been a long time under water and longing to get up, or you're terrified of something, and then suddenly everything just stops. And then, when you try to breathe in again, then you can't because it hurts so much..." (Case 9, 12 years)

Many of the children explained that it was painful to move and some experienced pain even when they were lying still in bed. One child who had undergone orthopaedic surgery explained:

C: "When I tried to move it was like I couldn't get anywhere. I tried to move, but then it tightened so that I couldn't move anywhere." (Case 1, 13 years)

Another child described his experience: 


\begin{abstract}
C: "It does hurt a little bit sometimes because I feel that I cannot find the correct position, but usually it goes pretty well when I achieve that position. It tightens a bit over the dressing and in my stomach.”; R: "Hmm, that doesn't sound very good."; C: "No it wasn't, so therefore I could not straighten my back." (Case 15, 9 years)
\end{abstract}

\title{
4.1.2 My feelings about pain
}

The children described their feelings about the pain experience using words such as disgusting, angry, scared, frightened, anxious, feeling down, depressed, upset, and afraid. They reported being afraid of feeling pain and that pain scared them. One child was scared and cried when she felt pain when she breathed:

R: "What did you do when it hurt to breathe?"; C: "I got very scared, and then I cried (...) And it was a really awful feeling. " (Case 9, 12 years)

Another child explained why she was scared:

R: "Did you get anything to drink down there then?", C: "I could, but I did not want to because I was a little bit scared, still”; R: "Yes. What were you afraid of?”; C: "Then I was a bit scared of - of what was going to happen, if something more would happen, that was even more painful and such" (Case 15, 9 years)

\subsubsection{Children's experiences with what felt unpleasant and painful aside from the surgical wound}

Children described having pain associated with their surgical wound, but others reported pain in other places too (Table 2). The most commonly reported issues were dizziness, having a sore throat or nausea. Children reported having a hoarse or thin voice and coughing a lot. One child described:

C: "I had a very sore throat, I remember. I had had something down my throat. So I coughed a lot, I remember." (Case 3, 14 years) 
Some of the children said that nausea and vomiting was painful:

C: "Of course it hurts an awful lot in your stomach when you throw up, because you sort of push on your stomach muscles... when you throw up and then you notice that it sort of really hurts a lot." (Case 9, 12 years)

Some of the children experienced nausea. Others were scared they might experience it. Some did not want to take pain medications or drink liquid because they were afraid of feeling sick and vomiting. One child said:

C: "I haven't been feeling sick in any way, but I was very afraid I might be. Because, when I had a surgery when I was five, I had to throw up immediately after surgery. After that, I have been anxious about feeling sick or throwing up (...) Yes. That was the only thing I was afraid of. I wasn't afraid of the operation." (Case 3, 14 years)

Many children had received midazolam as a premedication. They talked about how it felt to not remember, to feel dizzy, and to say funny things. Some described it as uncomfortable, strange or odd, and one reported it felt like she was drunk. One child said:

C: "It made me...I was completely paralyzed in my mouth. I could not speak."; R: "Yes.";

C: "I was sooo... and lots of mumbling (...) And then I do not remember anything from the

(...) For those tablets.”; R: “Yes mmm.”; C: “They made me totally...totally forgetful...so I do not remember anything at all."; R: "How was it then?"; C: "It felt strange." (Case 2, 11 years)

Some children reported having experienced double vision. For example, they saw two moms or that their mom had two noses. One child said:

C: "Mm I was dizzy, and eh...it hurt a bit in my arm (...) I had a headache, and I was seeing double of everything." (Case 9, 12 years) 
Some children had unexpected pain in areas other than their surgery wound, including pain in their back, shoulder or neck, inside their mouth, or heels (Table 2). One child explained:

C: "Then I noticed that I had a kind of blister on the inside of my mouth (...) They told me it was because I had a tube in my throat that went into my mouth...that created these blisters." (Case 5, 16 years)

C "I felt a bit of pain in my legs. So I moved them around a bit and...I had some pain in my heels. So, I just lifted my legs up a bit." (Case 5, 16 years)

\subsection{Children's experiences with pain management}

\subsubsection{Why I didn't tell the nurse when I was in pain}

Only five children remembered having used a pain assessment tool during their stay in the recovery unit. Some children told the nurses when they were in pain, while others did not. The children gave different explanations for why they did not tell the nurses about their pain. Some explained it was because the nurses had already asked them about their pain or they were waiting for the nurse to come and ask about it. Others waited to see if their pain got better or tried to endure it. Some believed the nurses could see when they were in pain:

R: "But do you think that someone in a way can see if you are in pain?"; C: "Yes I believe so...they came by and looked at me and checked. They looked at my pain-infusion pump and on the monitor where they saw if I was in pain or not." (Case 1, 13 years)

Some children said they did not report their pain to the nurses because they did not want to have analgesic drugs. One child explained:

R: "But have you told someone?"; C: "Um, sometimes. It is a bit difficult."; R: "Why is it difficult?"; C: "Because I didn't want to have some...have some medication or because...yes 
I become nauseous and I don't like that."; $R$ : "So you did not really want the painkillers that they could give you?"; C: "No." (Case 15, 9 years)

\subsubsection{The medicines they gave me to help with my pain}

Most of the children reported receiving pain medication from the nurses (Table 1) and that this helped with their pain. One child described:

R: "What do the nurses do then?"; C: "They give you medicine and...if you are in pain they make sure that you are not in pain." (Case 4, 8 years)

The children described receiving pain medication in different ways. Some reported that it was difficult to swallow tablets:

C: "I got painkillers, but I couldn't swallow it and then (...)"; $R$ : "What did they do when you couldn't swallow it?"; C: "They tried to split it."; R: "Yes, and was that better? "; C:

“No.”, R: "But did you get some other painkiller instead?" (shakes head) (Case 20, 12 years)

Some children spoke spontaneously about how unpleasant it was to receive a rectal suppository:

C: "The pills helped a little, the ones they stuck in my bum. But it was really uncomfortable! It hurt a little when they didn't get it in the right place and stuff like that, that's when I started going 'ow it hurts'." (Case 11, 9 years)

Some of the children had epidural anaesthesia or a neural blockade and described how it felt. Some were more prepared than others:

C: "Feels like my feet had fallen asleep (...)"; $R$ : "What do you think would have helped you most when you were in pain? After the surgery?"; C: "Mm for example, before each time I was going to move, so I had a kind of button that I could press on, to get a little extra." (Case 5, 16 years) 
Another said:
R: "Did you feel any pain when you woke up?"; C: "Nothing! I...they anesthetized the nerves from the knee and down. So I had...I was totally paralyzed, throughout from the knee down...until today around 12 o'clock. Then I began to move a little bit on my toes, and now I've got back ninety percent of the feeling. It hurts! (...)”; R: "Did you know about this before?"; C: "No, I wondered what it was.” (Case 3, 14 years)

\subsubsection{Other things that helped me cope with my pain}

The children described different non-pharmacological pain relief methods that were helpful. The children used positioning, relaxation, and distraction most frequently. Some reported that changing their position helped, and some stated that they tried to lay still and not move to reduce their pain:

R: "It helps, to change positions?"; C: "Yes...mmm."; R: “Are there any other things that can help? ”; C: “Yes...sometimes it may be okay to lie still.” (Case 7, 13 years)

The children reported that relaxation was a useful method of pain relief; one described:

C: “...to relax and not to think too much about it and be in my own world (...) I close my eyes and think of something else...think of something that I like or someone that I love or something I like to do or such." (Case 9, 12 years)

Many children described thinking about something else, something they liked to do or someone they loved. The children reported using different distraction techniques once they were on the recovery ward. The methods they used included playing games on a mobile phone or tablet, watching films or YouTube, or checking Instagram and Snapchat.

The children described the nurses using different non-pharmacological methods. Positioning, heat, and cold were the most frequently used methods in the recovery unit. The 
children reported that the nurses helped them find a position that relieved their pain. One boy, who felt better when putting his operated foot on a pillow, said:

$$
\begin{aligned}
& \text { C: "They [nurses] put it [his foot] on a pillow (...) They do things so that it's not that } \\
& \text { painful anymore." (Case 16, } 9 \text { years) }
\end{aligned}
$$

Another child described her experience with receiving ice cubes after tonsillectomy:

R: "You know, we've talked about a lot of...uh, and the ice cubes and such?"; C: "That helped a little, but not a lot but it...it helped so that it got, it got a bit better in my throat. But not a huge lot, but it helped a little, I thought." (Case 11, 9 years)

Many children said that their parents could not do much to help them cope with their pain, because their parents did not know what to do. However, they gave examples that illustrated that having their parents there helped. The children reported that parents' use of emotional support and help with daily activity and positioning were the methods used most often:

R: "Was there anything they did then, which helped?"; C: "Yes...like... when I needed it, they gave me some water to drink, or massaged my feet or something like that."; R: "Yes. Mmm. And it also helped a little?"; C: "Yes." (Case 5, 16 years)

Not all methods helped. One child explained:

R: "Has your mom done something that has helped you?"; C: "She tried, but it didn't work."; R: "What did Mom try to do?"; C: "She tried to say that I had to breathe in and out very slowly." (Case 14, 9 years)

\subsubsection{What helped me feel safe and secure}

The children spoke about feeling safe while their parents were together with them. They explained that this was because they did not want to be alone and their parents could get help for them or talk to them and explain what was happening. One child explained how it felt to have her mother there: 
C: "It was ok to have someone there...I didn't have to be alone (...) It feels safe." (Case 18, 16 years)

Some children also explained how they felt when their parents were not bedside when they awoke in the recovery unit:

C: "I remember when I woke up and then I yelled at a nurse and said: 'Isn't it your job to ensure that Mom and Dad should be here now'...I did react that they weren't there when I woke up. I could see that all the others had their parents with them." (Case 3, 14 years)

The children also indicated that the nurses' presence helped them feel safe and secure. One child said:

R: "What did the nurses do, did they do something more?"; C: "No, but they were there the whole time."; R: “Mmm, so you felt that they looked after you?”; C: "Yes (...)”; R: Do you remember if there were anyone else but Mom there?"; C: "It was a man...and many nurses there...I do not remember more."; R: "No, no, so you felt that it was..."; C: "Safe." (Case 12,11 years)

\subsection{Children's recommendations for future pain management}

The children's recommendations to nurses and other children were based on their own experiences and what they had found helpful when coping with their postoperative pain.

\subsubsection{Things I would have liked nurses to do to help me with my pain}

The children's recommendations to nurses focused on providing more preparatory information, such as what was going to happen, that it would hurt after surgery, and to not drink too much after surgery because it might make you feel sick. One child said:

C: "That it will hurt a bit after surgery." (Case 12, 11 years)

Another said: 
C: "Tell about the tube you put down our throat." (Case 1, 13 years)

They also wanted the nurses to be with them and talk to them, to give them pain medication when they needed it, and to ensure that their parents are present when they awaken after surgery. One child said:

C: "Give medicine when we need it." (Case 6, 11 years)

Another said:

C: "I wish Mom and Dad were there when I woke up." (Case 3, 14 years)

\subsubsection{What children having surgery in the future need to know}

The children also gave recommendations for other children who are going to have surgery. Their recommendations were about how they could distract themselves from the pain by thinking of something else, thinking of something nice, or talking to someone:

C: "Try to think of something else, not to think about that you are in pain or have a sore throat or something, try to do something else, so you forget, it helped for me when I started reading a book. It got better." (Case 11, 9 years)

They also recommended staying calm, trying to sleep, taking medicine, and not looking at the syringe. One child said:

$$
\text { C: “Try to sleep." (Case 8, } 9 \text { years) }
$$

Another child:

C: "Do not look at the syringe-look at your dad instead." (Case 17, 9 years)

\section{DISCUSSION}

More than half of the children in this study experienced moderate to severe pain during their time in the recovery unit. Many of them did not tell their nurses when they were in pain and pain assessment tools do not appear to have been used routinely. The children also experienced pain in 
places other than the surgical wound and reported that nausea and vomiting felt unpleasant and was sometimes worse than the pain itself. The children indicated that pain medications and nonpharmacological pain relief methods helped them cope with their pain. The children provided several recommendations for nurses and for other children about how to improve postoperative pain management.

\subsection{Children's experiences with pain}

The finding that children in our study experienced moderate to severe postoperative pain is consistent with other recent studies that used a retrospective chart review (Avian et al. 2016), a prospective chart review (Kozlowski et al. 2014) or interviewed parents and children (Birnie et al. 2014, Thienthong et al. 2014). It is noteworthy that the children in our study also described feeling unpleasant or pain in areas other than their surgical wound. Many children described having a sore throat, hoarseness, nausea, vomiting, headaches, dizziness, disorientation, or impaired vision as unpleasant or painful. These are all common after anaesthesia and intubation (Falk et al. 2018).

A sore throat is the most common adverse event related to endotracheal intubation (Biro et al. 2005, Hu et al. 2013, Jaensson et al. 2010), yet very few of the children in this study reported being prepared for this. More than half the children in this study experienced postoperative nausea and vomiting (PONV), and described it as unpleasant or painful, has also been reported previously (Kozlowski et al. 2014, Rullander et al. 2013). In a study by Kozlowski et al. (2014), 44\% of children experienced nausea and vomiting. PONV can increase pain (APA 2016, Rullander et al. 2013) and prevent effective pain relief (Feinleib et al. 2018). Some children in this study did not tell the nurse when they were in pain because they were afraid of receiving pain medications that could cause nausea or vomiting. Even though almost half of these children experienced nausea and vomiting, only six were prescribed antiemetic medication and only three received this medication. Multimodal postoperative pain control strategies that reduce opioid administration should reduce the incidence of PONV (Feinleib et al. 2018), but less than half of the children received both 
paracetamol and an NSAID. PONV is a patient-important outcome and common side-effect after anaesthesia, and it is important to identify risk factors relating to patient, anaesthetic and type and length of surgery (Feinleib et al. 2018). There is a need for healthcare professionals to be aware of children's anxiety about PONV, prevent and treat PONV.

Interestingly, our study shows that children complained about back pain in addition to pain in their neck or shoulder and sore heels (i.e. pain in places other than the surgical wound). This pain may be due to patient positioning and immobilisation during surgery. Immobilisation places patients at risk for skin and underlying tissue injury during anaesthesia and is well known for causing complications (Welch et al. 2018). Optimal positioning during surgery, and preventing injury and complications, are responsibilities shared by the surgeon, anaesthetist, and operating room nurses. Healthcare professionals should focus on these issues and prevent immobilisation complications.

Many of the children in this study reported experiencing dizziness and disorientation preoperatively, after receiving a premedication such as midazolam. They described having double vision, saying funny things, and not remembering things, and that these were strange, odd, and uncomfortable experiences. Lack of bodily control may feel scary and result in increased anxiety (Rullander et al. 2013), possibly preventing children from coping with the situation (Panella 2016). There is a need to enhance the use of preparatory information, to focus on preventing complications after anaesthesia, and to treat PONV.

\subsection{Children need to be prepared for surgery}

Even though most of these children had elective surgery, we found they lacked preparatory information about pain (e.g. how much pain they would experience, where to expect pain, how long it would last), what would happen during their hospital stay, pharmacological management, and, for example, how it would feel after having a neural blockade. The children felt unprepared for their postoperative experience and said that they needed more information before the surgery. Many of 
the children experienced side effects after anaesthesia, and even the most common, such as sore throat and nausea, had not been explained to them. Some children asked for an explanation from their parents or a nurse, while others did not. For example, one child who had a sore throat and did not know why asked the nurse, who explained that it was because they had "put an air tube in your throat”. Lack of preparatory information has also been reported in similar studies (Ford et al. 2012, Twycross \& Finley 2013). Insufficient preparatory information may lead to increased anxiety and pain (Fortier et al. 2010, Panella 2016), which increases the risk of CPSP (Rabbitts et al. 2017).

Preparatory information about the operation itself, how much it will hurt afterwards and for how long, and what will be done to ease the pain are important and having this information benefits children (Lerman et al. 2016). The information must be age-appropriate and repeated often to ensure that the child understands (Panella 2016). Preparatory information may reduce anxiety and help children cope (Manyande et al. 2015). Additionally, children who are well prepared may not need premedication, such as midazolam, and may require less use of opioids postoperatively (Panella 2016). Interventions such as videos and interactive games appear to be effective at reducing children's preoperative anxiety (Chow et al. 2016, Manyande et al. 2015) and their use should be encouraged by nurses. Interestingly, one of the included hospitals have an evidence-based guideline on how to prepare children in different age groups for surgery. This guideline includes what to inform about, how to prepare them, and how to use different preparatory videos, preparatory picture-books and hospital equipment. Apparently, not many nurses used this guideline to prepare the children for surgery. The children have rights to be consulted about the things that affect them and they need to be explained what is happening to them during the hospital stay (Regulation on Children's Stay in Hospitals 2000). The nurses working in the recovery units should communicate with the children about their experience and explain why they have pain other places than the surgery wound, why they cannot move their leg because they have got neural blockade and so forth. 


\subsection{Children do not always tell the nurses when they are in pain}

One important finding from this study was that many of the children did not tell their nurses when they were in pain. Several explanations were given for this. Some children believed the nurses could see that they were in pain, others tried to wait and see if it got better, or they tried to endure the pain or to wait for the nurses to come and ask about their pain. Some children did not want pain medication because they were afraid of nausea or vomiting. This suggests that nausea and vomiting are considered as bad as or worse than pain, which concurs with the results of a previous study (Rullander et al. 2013).

Very few children in this study remember having their pain assessed with tools, which is consistent with previous studies (Birnie et al. 2014, Ford et al. 2012, Smyth et al. 2011, Twycross \& Collis 2013). This may be because pain assessment tools are unavailable on the unit (Smeland et al. 2018) or because nurses lack knowledge about how children of different ages express their pain and may expect that children will tell them when they are in pain (Rullander et al. 2013). It has also been demonstrated in other studies (Pope et al. 2017, von Baeyer et al. 2017) that children are able to verbally communicate about their pain intensity from around age 4-5 years. One strategy that helps nurses communicate with children about their pain is the use of valid, age-appropriate pain assessment tools (Hauer et al. 2018).

If nurses do not use pain assessment tools or ask children about their pain intensity and location, they will not know where or how much pain the child is experiencing. This may mean that children experience unnecessary pain (Sng et al. 2013, Twycross \& Finley 2013). Strategies are needed to enhance nurses' pain assessment practices, by involving the children themselves and using appropriate tools to assess pain regularly. There is also a need to explore the reasons nurses do not routinely use pain assessment tools.

\subsection{What children think is helpful when they are in pain}


The children reported that non-pharmacological pain relief methods were helpful for managing their pain. The children most frequently described nurses using non-pharmacological methods such as positioning, being present, and applying heat and cold; they also pointed out that they needed more preparatory information. In this study, children identified their parents' presence as being crucial for feeling safe and secure and for helping them cope with their pain. Most, but not all parents were by their child's bedside when they woke up after surgery. The children pointed out that it was important to them that their parents were there when they awoke, because they helped the child by explaining what had happened, comforted them, and helped them with daily activities. This concurs with the results of previous studies (He et al. 2007, Idvall et al. 2005, Polkki et al. 2003). Reasons for parents' late arrivals at the recovery unit included: not receiving the message to come to the recovery unit; nurses who were too busy in the ward to show the parents to the recovery unit; long distances between the ward and recovery unit; and that parents became lost on their way to the recovery unit. Another contributing factor might be the recovery nurses' attitudes about having parents present, despite the fact that nurses should encourage parents to be bedside in the recovery units and to remain with their child whenever feasible (Panella 2016). Organizational barriers that prevent parents' presence in the recovery units need to be identified and addressed.

In this study, very few children commented on the environment, which is not in line with a study by Polkki et al. (2003), where children recommended that nurses create a more comfortable environment. This may be because nursing practices have changed since the earlier study, with greater focus now being placed on the use of non-pharmacological methods. Alternatively, the nurses in this study may have been particularly good at creating a comfortable environment. Twycross and Collis (2013) found that nurses seldom used non-pharmacological methods to reduce pain, which, again, differs from our results. Reasons for these differences may include that nurses working in recovery units are with the child almost all the time, whereas in the ward the parents are 
with their children most of the time and the nurses are only there for short periods. This creates a situation where parents may carry out most of the non-pharmacological pain relief on the ward.

In this study the children discussed non-pharmacological strategies that they thought were helpful. Other non-pharmacological strategies that may reduce pain were not mentioned, for example guided imagery (Woragidpoonpol et al. 2013). Animal-assisted intervention, may reduce distress for children undergoing painful procedures (Vagnoli et al. 2015), but was not in use in the hospitals in Norway at the time this study was carried out. Further research is needed to explore children's experiences about using these non-pharmacological strategies to relieve postoperative pain.

The children in our study indicated that it was difficult to swallow tablets and unpleasant to receive a rectal suppository. Despite there being many ways to administer pain medication, the children who could not swallow tablets were not offered an alternative. This is especially concerning in relation to young children who are usually unable to swallow tablets and may mean that they are not receiving adequate pain medications. This issue was exacerbated by the fact that many of these children had experienced, or were afraid of, nausea and vomiting. This made swallowing tablets even more difficult. Previous studies have reported that nurses lack the necessary knowledge about analgesics (Ekim \& Ocakc1 2013, Hovde et al. 2012, Lunsford 2015, Smeland et al. 2018), which may be one reason why children were not offered other options. Alternatively, the medication may not have been prescribed or available to administer via these routes. The children reported that both non-pharmacological and pharmacological pain relief methods were helpful; they also challenged nurses to ensure that their parents are present when children awaken after surgery, provide more preparatory information, and administer pain medications using more suitable methods.

\subsection{The nurses would make sure you're not in pain}


In this study, some children reported that if they were in pain, the nurses would make sure their pain was treated, implying that if there was anything else to be done the nurses would do it. Rullander et al. (2013) found that parents lacked confidence in nurses' technical and treatment skills but that both parents and children rated their hospital experience as relatively satisfactory. The inconsistency between children experiencing moderate and severe pain while reporting being satisfied with their care replicates the results of another study (Twycross \& Finley 2013). This finding is of concern because if children expect to experience severe pain postoperatively and do not tell their nurses about it, this may contribute to ongoing undertreatment of children's pain. There is a need to encourage healthcare professionals to communicate with the children about their pain experience, and to ensure them that their pain can be relieved.

Assessment and management of pain are essential to paediatric postoperative care (Anand et al. 2018, Hauer et al. 2018). Nurses, and other healthcare professionals, have a responsibility to ensure optimal postoperative pain management. This study suggests that current pain assessment and management practices are suboptimal and do not adhere to clinical guidelines in many areas. For example, few children were assessed as using pain assessment tools and half experienced PONV. Despite this, there was a belief among many of the children that their nurses would have relieved their pain if they had been able to do so. There is a need to prevent unnecessary suffering and to encourage nurses and other healthcare professionals to talk to their child patients and their parents about their expectations and pain management. Future research should explore why healthcare professionals do not communicate with children about the children's pain experience.

\subsection{Strengths and limitations}

There were some limitations to this study. Firstly, our participants were interviewed in the hospital — an unfamiliar setting — and had not previously met the interviewers. However, both interviewers had experience working with children and used a variety of strategies to gain the children's trust and build rapport before starting the interview. The interviewer assured the children that they could 
stop or take a break at any time during the interview. The children could also choose to have their parents present. Secondly, because the interviews were undertaken while the children were still in the hospital, this may mean the children provided favourable answers because of this. This may result in a positive response bias, especially if there was a perception that their answers might affect their care. However, the interviewers were not part of the nursing team and reassured the children before the interview that there were no right or wrong answers and assured that the care they received would not be influenced by whether or not they took part in the study.

Thirdly, these children were 8-16 years old and underwent a range of surgical procedures; it is possible that this influenced individual responses. Nevertheless, exploring their breadth of pain experiences provides valuable information about children's experiences across these contexts. Fourthly, the interviews were conducted at two hospitals within a relatively short time frame. To reduce information bias, the same two interviewers were present during all interviews: one interviewing and one observing. At the end of the interviews, the observer asked questions if something had been forgotten or was unclear, increasing the likelihood that areas identified in the interview guide were addressed. This study provides a useful insight into children's views about their pain management experiences in the recovery unit and identifies areas for further research and ways in which clinical practice can be improved.

\section{CONCLUSION}

This study provides evidence that paediatric postoperative pain management remains suboptimal. Half of these children experienced moderate to severe postsurgical pain, few were assessed with a pain assessment tool, many received insufficient pain medication, and there was a lack of preparatory information provided. The children experienced pain associated with the surgical wound as well as pain in other locations. They explained why they did not always tell the nurses when they were in pain. 
The children challenged nurses to use more non-pharmacological strategies, especially preparatory information, and to ensure parents are present when children awaken after surgery. Increased awareness among nurses about the importance of parental presence may prevent children from awakening alone, afraid, and insecure. This study also shows that nurses alleviate postoperative pain by administering analgesics, although the children did not always receive medication appropriately (e.g. being given tablets when they could not swallow). The children in this study provided suggestions to nurses and to other children undergoing surgery on ways to improve postoperative pain relief and pain management.

\section{RELEVANCE TO CLINICAL PRACTICE}

This study provides further evidence that children experience moderate to severe pain in the recovery unit after surgery and do not always tell their nurses when they are in pain. These results provide additional evidence that nurses appear not to use pain assessment tools routinely. In Norway there are for the time being no national guidelines in paediatric postoperative pain management. Hospital policies and strategies are needed to enhance nurses' pain assessment practices, including involving the children themselves, using appropriate tools, and assessing pain regularly. There is also a need for establishing a child and youth advisory group at the hospitals to ensure children's rights and that Regulations on Children's Stay in Hospitals are met. Further studies exploring nurses' perspectives on children's rights versus paternalistic decision making may contribute to a better understanding of nurses' choices of action. Children report that the use of nonpharmacological pain-relieving strategies helps them cope with pain. Given this, nurses should be encouraged to increase their use of non-pharmacological strategies, including preparatory information and education for children and their parents about postoperative pain management. Doing so will enhance paediatric pain management. Parents should always be at the child's bedside in the recovery unit when the child awakens postoperatively and should be encouraged to remain with their child whenever feasible. 
PONV and other well-known post-anaesthetic side effects can worsen children's pain at the

very time when providing good pain relief is the priority and should thus be prevented or treated.

\section{REFERENCES}

Anand KJS, Gracia-Preats JA \& Kim MS (2018) Assessment of neonatal pain. In UpToDate, (Retrieved from) http://www.uptodate.com/contents/assessment-of-neonatal-pain

APA (2016): Guidelines on the prevention of Post-operative Vometing in Children. http://www.apagbi.org.uk/sites/default/files/APA_Guidelines_on_the_Prevention_of_Postoperative Vomiting in Children.pdf

Avian A, Messerer B, Wunsch G, Weinberg A, Kiesling AS \& Berghold A (2016): Postoperative paediatric pain prevalence: A retrospective analysis in a university teaching hospital. International Journal of Nursing Studies 62, 36-43, http://ovidsp.ovid.com/ovidweb.cgi? $\mathrm{T}=\mathrm{JS} \& \mathrm{CSC}=\mathrm{Y} \& \mathrm{NEWS}=\mathrm{N} \& \mathrm{PAGE}=$ fulltext $\& \mathrm{D}=$ emexa\&AN=6 17332548

Batoz H, Semjen F, Bordes-Demolis M, Bénard A, Nouette-Gaulain K \& Absalom AR (2016): Chronic postsurgical pain in children: prevalence and risk factors. A prospective observational study. BJA: British Journal of Anaesthesia 117, 489-496.10.1093/bja/aew260

Birnie K, Chambers C, Fernandez C, Forgeron P, Latimer M, McGrath P, Cummings E \& Finley A (2014): Hospitalized children continue to report undertreated and preventable pain/Les enfants hospitalisés continuent de signaler des douleurs non traitées et évitables. Pain Research \& Management : The Journal of the Canadian Pain Society 19, 198-204,

Biro P, Seifert B \& Pasch T (2005): Complaints of sore throat after tracheal intubation: a prospective evaluation. European Journal of Anaesthesiology 22, 307-311,

Chow CH, Van Lieshout RJ, Schmidt LA, Dobson KG \& Buckley N (2016): Systematic Review: Audiovisual Interventions for Reducing Preoperative Anxiety in Children Undergoing Elective Surgery. Journal of Pediatric Psychology 41, 182-203.http://dx.doi.org/10.1093/jpepsy/jsv094

Ekim A \& Ocakc1 AF (2013): Knowledge and Attitudes Regarding Pain Management of Pediatric Nurses in Turkey. Pain Management Nursing 14, 262-267.http://dx.doi.org/10.1016/j.pmn.2012.02.004

Falk SA, Fleisher LA, Jones SB \& Nussmeier NA (2018) Overview of anesthesia. In UpToDate, (Retrieved from) https://www.uptodate.com/contents/overview-of-anesthesia-and-anestheticchoices? source $=$ search result\&search $=$ complications $\% 20$ after\%20anesthesia\&selectedTitle $=1 \sim 150$

Feinleib J, Kwan LH, Yamani A, Holt NF, Davidson A \& Crowley M (2018) Postoperative nausea and vomiting. In UpToDate, (Retrieved from) https://www.uptodate.com/contents/postoperative-nauseaand-vomiting

Ford K, Courtney-Pratt H \& FitzGerald M (2012): Post-discharge experiences of children and their families following children's surgery. Journal of Child Health Care 16, 320330.10.1177/1367493512448129

Fortier MA, Del Rosario AM, Martin SR \& Kain ZN (2010): Perioperative anxiety in children. Paediatric Anaesthesia 20, 318-322.http://dx.doi.org/10.1111/j.1460-9592.2010.03263.x

Hauer J, Jones BL, Poplack DG \& Armsby C (2018) Evaluation and management of pain in children. In UpToDate, (Retrieved from) http://www.uptodate.com/contents/evaluation-and-management-ofpain-in-children?source $=$ search result\&search $=$ PAIN + CHILDREN\&selectedTitle $=1 \% 7 \mathrm{E} 150$

He HG, Vehvilainen-Julkunen K, Polkki T \& Pietila AM (2007): Children's perceptions on the implementation of methods for their postoperative pain alleviation: an interview study. International Journal of Nursing Practice 13, 89-99, http://onlinelibrary.wiley.com/store/10.1111/j.1440172X.2007.00614.x/asset/j.1440172X.2007.00614.x.pdf? $\mathrm{v}=1 \& \mathrm{t}=\mathrm{j} 31 \mathrm{n} 2 \mathrm{asq} \& \mathrm{~s}=318 \mathrm{a} 77 \mathrm{ed} 87034 \mathrm{fe} 9 \mathrm{~cd} 77 \mathrm{a} 51 \mathrm{~b} 4 \mathrm{cfb} 369 \mathrm{db} 9 \mathrm{c} 17 \mathrm{be} 8$

Hicks CL, von Baeyer CL, Spafford PA, van Korlaar I \& Goodenough B (2001): The Faces Pain Scale Revised: toward a common metric in pediatric pain measurement. Pain 93, 173183.http://dx.doi.org/10.1016/S0304-3959(01)00314-1 
Hovde KR, Granheim TH, Christophersen K-A \& Dihle A (2012): The Norwegian version of the Pediatric Nurses' Knowledge and Attitudes Survey Regarding Pain: reliability and validity. Pediatric Nursing 38, 264-269, http://www.ncbi.nlm.nih.gov/pubmed/23189777

Hu B, Bao R, Wang X, Liu S, Tao T, Xie Q, Yu X, Li J, Bo L \& Deng X (2013): The size of endotracheal tube and sore throat after surgery: a systematic review and meta-analysis. PloS One $\mathbf{8}$, e74467.10.1371/journal.pone.0074467

IASP (2017): Pain After Surgery in Children and Infants: Fact Sheets NO.7. Global Year Against Pain After Surgery 2017. (Retrieved from). http://www.iasppain.org/Advocacy/GYAP2016.aspx?ItemNumber $=5718$

Idvall E, Holm C \& Runeson I (2005): Pain experiences and non-pharmacological strategies for pain management after tonsillectomy: a qualitative interview study of children and parents. Journal of child health care : for professionals working with children in the hospital and community 9, 196, http://chc.sagepub.com/content/9/3/196.full.pdf

International Association for the Study of Pain Task Force on T (2018), http://www.iasppain.org/Education/Content.aspx? ItemNumber $=1698$

Jaensson M, Olowsson LL \& Nilsson U (2010): Endotracheal tube size and sore throat following surgery: a randomized-controlled study. Acta Anaesthesiologica Scandinavica 54, 147-153.10.1111/j.13996576.2009.02166.x

Kozlowski LJ, Kost-Byerly S, Colantuoni E, Thompson CB, Vasquenza KJ, Rothman SK, Billett C, White ED, Yaster M \& Monitto CL (2014): Pain Prevalence, Intensity, Assessment and Management in a Hospitalized Pediatric Population. Pain Management Nursing 15, 22-35.10.1016/j.pmn.2012.04.003

Lerman J, Coté CJ \& Steward DJ (2016) Manual of Pediatric Anesthesia, 7th ed. 2016. edn. Springer International Publishing : Imprint: Springer, http://www.springer.com/gp/book/9783319306827

Ljusegren G, Johansson I, Gimbler Berglund I \& Enskar K (2012): Nurses' experiences of caring for children in pain. Child Care Health Dev 38, 464-470.10.1111/j.1365-2214.2011.01262.x

Lunsford L (2015): Knowledge and Attitudes Regarding Pediatric Pain in Mongolian Nurses. Pain Management Nursing 16, 346-353.10.1016/j.pmn.2014.08.007

Manyande A, Cyna AM, Yip P, Chooi C \& Middleton P (2015) Non-pharmacological interventions for assisting the induction of anaesthesia in children. In Cochrane Database of Systematic Reviews. John Wiley \& Sons, Ltd.10.1002/14651858.CD006447.pub3

Mennella HDMA-B \& Heering HRC (2017) Pain Assessment in Children. EBSCO Publishing, Ipswich, Massachusetts, http://search.ebscohost.com/login.aspx?direct=true \&db=nup\&AN=T700311\&site=nuplive\&scope $=$ site

Ortiz MI, Ponce-Monter HA, Rangel-Flores E, Castro-Gamez B, Romero-Quezada LC, O'Brien JP, RomoHernandez G \& Escamilla-Acosta MA (2015): Nurses' and nursing students' knowledge and attitudes regarding pediatric pain.(Research Article)(Report). Nursing Research and Practice. $10.1155 / 2015 / 210860$

Panella JJ (2016): Preoperative Care of Children: Strategies From a Child Life Perspective. AORN Journal 104, 11-22.10.1016/j.aorn.2016.05.004

Polkki T, Pietila AM \& Vehvilainen-Julkunen K (2003): Hospitalized children's descriptions of their experiences with postsurgical pain relieving methods. International Journal of Nursing Studies 40, 33-44, http://ac.els-cdn.com/S0020748902000305/1-s2.0-S0020748902000305main.pdf? tid=597ff2f4-3fc1-11e7-a58700000aacb35f\&acdnat $=1495548712$ a049 $d 19 c d 4 c 0 d 041$ e4d474b5bfb61290

Pope N, Tallon M, McConigley R, Leslie G \& Wilson S (2017): Experiences of acute pain in children who present to a healthcare facility for treatment: a systematic review of qualitative evidence. $J B I$ Database System Rev Implement Rep 15, 1612-1644.10.11124/jbisrir-2016-003029

Rabbitts JA, Fisher E, Rosenbloom BN \& Palermo TM (2017): Prevalence and Predictors of Chronic Postsurgical Pain in Children: A Systematic Review and Meta-Analysis. Journal of Pain 18, 605614.10.1016/j.jpain.2017.03.007

Regulation on Children's Stay in Hospitals, Forskrift om barns opphold i helseinstitusjon (2000) Forskrift om barns opphold i helseinstitusjon (FOR-2000-12-01-1217) (Retrievd form) https://ovdata.no/dokument/SF/forskrift/2000-12-01-1217 
Royal College of Nursing (2009) The Recognition and Assessment of Pain in Children: Update of full guideline. RCN Publishing, London.

Rullander AC, Jonsson H, Lundstrom M \& Lindh V (2013): Young people's experiences with scoliosis surgery: a survey of pain, nausea, and global satisfaction. Orthopaedic Nursing 32, 327-333; quiz 334-325.10.1097/nor.0000000000000007

Schug SA \& Bruce J (2017): Risk stratification for the development of chronic postsurgical pain. PAIN Reports 2, e627.10.1097/pr9.0000000000000627

Smeland AH, Twycross A, Lundeberg S \& Rustøen T (2018): Nurses' Knowledge, Attitudes and Clinical Practice in Pedatric Postoperative Pain Management. Pain Management Nursing.10.1016/j.pmn.2018.04.006

Smyth W, Toombes J \& Usher K (2011): Children's postoperative pro re nata (PRN) analgesia: Nurses' administration practices. Contemporary Nurse 37, 160-172.10.5172/conu.2011.37.2.160

Sng QW, He HG, Wang W, Taylor B, Chow A, Klainin-Yobas P \& Zhu L (2017): A Meta-Synthesis of Children's Experiences of Postoperative Pain Management. Worldviews on Evidence-Based Nursing 14, 46-54, http://ovidsp.ovid.com/ovidweb.cgi?T=JS\&CSC=Y\&NEWS=N\&PAGE=fulltext\&D=medl\&AN=27 930859

Sng QW, Taylor B, Liam JL, Klainin-Yobas P, Wang W \& He HG (2013): Postoperative pain management experiences among school-aged children: A qualitative study. Journal of Clinical Nursing 22, 958968.http://dx.doi.org/10.1111/jocn.12052

Stanley M \& Pollard D (2013): Relationship between knowledge, attitudes, and self-efficacy of nurses in the management of pediatric pain.(Continuing Nursing Education)(Report). Pediatric Nursing 39, 165,

Thienthong S, Sriraj W, Siripul P, Finley A, Boonyawattanangkool K \& Kasetwetin S (2014) A survey of postoperative pediatric pain management among seven hospitals in northeastern Thailand.

Twycross A \& Collis S (2013): How well is acute pain in children managed? A snapshot in one English hospital. Pain Management Nursing 14, e204-215.10.1016/j.pmn.2012.01.003

Twycross A \& Finley GA (2013): Children's and parents' perceptions of postoperative pain management: a mixed methods study. Journal of Clinical Nursing 22, 3095-3108.10.1111/jocn.12152

Twycross A, Forgeron P \& Williams A (2015): Paediatric nurses' postoperative pain management practices in hospital based non-critical care settings: A narrative review. International Journal of Nursing Studies 52, 836, http://ac.els-cdn.com/S0020748915000103/1-s2.0-S0020748915000103main.pdf? tid=ae514cd8-39e6-11e6-bd8f00000aacb35d\&acdnat $=1466757541$ c800f7a2d8454e40208e5c07093a147a

Twycross A \& Williams A (2014) Pain: A Biopsychosocial Phenomenon. In Managing Pain in Children. A Clinical Guide for Nurses and Healthcare Professionals 2edn (Twycross A, Dowden, S., \& Stinson, J. ed.). Wiley Blackwell, West Sussex UK, pp. 36-49.

Vagnoli L, Caprilli S, Vernucci C, Zagni S, Mugnai F \& Messeri A (2015): Can Presence of a Dog Reduce Pain and Distress in Children during Venipuncture? Pain Management Nursing 16, 8995.https://doi.org/10.1016/i.pmn.2014.04.004

von Baeyer CL, Jaaniste T, Vo HL, Brunsdon G, Hsuan-Chih Lao A \& Champion GD (2017): Systematic review of self-report measures of pain intensity in 3- and 4-year-olds: Bridging a period of rapid cognitive development. The journal of pain : official journal of the American Pain Society, http:/www.epistemonikos.org/documents/5b3ccd7c0505c5f3ef2589a493af627656b78772

von Baeyer CL, Spagrud LJ, McCormick JC, Choo E, Neville K \& Connelly MA (2009): Three new datasets supporting use of the Numerical Rating Scale (NRS-11) for children's self-reports of pain intensity.

Pain 143, 223-227.http://dx.doi.org/10.1016/j.pain.2009.03.002

Welch MB, Wahr JA \& Crowley M (2018) Patient positioning for surgery and anesthesia in adults. In UpToDate, (Retrieved from) https:/www.uptodate.com/contents/patient-positioning-for-surgeryand-anesthesia-inadults?source $=$ search result\&search $=$ Patient $\% 20$ positioning $\% 20$ for $\% 20$ surgery $\% 20$ and $\% 20$ anesthe sia $\% 20$ in $\% 20$ adults\&selectedTitle $=1 \sim 150$

Woragidpoonpol P, Yenbut J, Picheansathian W \& Klunklin P (2013): Effectiveness of non-pharmacological interventions in relieving children's postoperative pain: a systematic review. JBI Database of Systematic Reviews and Implementation Reports 11, 117-156.10.11124/jbisrir-2013-926 


\section{What does this paper contribute to the wider global clinical community?}

- The children in this study experienced moderate to severe pain and had pain in places other than their surgical wound site.

- The children did not always tell their nurses when they were in pain, and explained why.

- The children provided useful suggestions about how to improve pediatric postoperative pain management. 
TABLE 1 Participant background characteristics $(\mathrm{N}=20)$

\begin{tabular}{|c|c|}
\hline Age & Number (\%) \\
\hline $8-11$ & $12(60)$ \\
\hline $12-16$ & $8(40)$ \\
\hline \multicolumn{2}{|l|}{ Gender } \\
\hline Female & $11(55)$ \\
\hline Male & $9(45)$ \\
\hline \multicolumn{2}{|l|}{ Type of surgery } \\
\hline Orthopaedic surgery & $11(55)$ \\
\hline Ear/Nose/Throat surgery & $3(15)$ \\
\hline Gastrointestinal surgery & $5(25)$ \\
\hline Neurosurgery & $1(5)$ \\
\hline \multicolumn{2}{|l|}{ Type of admission } \\
\hline Elective surgery & $10(50)$ \\
\hline Elective day surgery & $6(30)$ \\
\hline Emergency surgery & $4(20)$ \\
\hline \multicolumn{2}{|l|}{ Type of medication received } \\
\hline Paracetamol & $14(70)$ \\
\hline Cox-inhibitors (NSAIDs) & $8(40)$ \\
\hline Opioid & $11(55)$ \\
\hline Morphine infusion & $1(5)$ \\
\hline Antiemetic & $3(15)$ \\
\hline Midazolam (premedication) & $7(35)$ \\
\hline Epidural anaesthesia & $3(15)$ \\
\hline Neural blockade & $1(5)$ \\
\hline
\end{tabular}


TABLE 2 The children's reported worst pain intensity and pain location experienced in the recovery unit $(\mathrm{N}=20)$

\begin{tabular}{|c|c|}
\hline & Number of children $(\%)$ \\
\hline Pain intensity & \\
\hline No pain $(0)$ & $3(15)$ \\
\hline Mild pain (1-3) & $6(30)$ \\
\hline Moderate pain (4-6) & $5(25)$ \\
\hline Severe pain $(7-10)$ & $5(25)$ \\
\hline Do not remember & $1(5)$ \\
\hline Pain in surgical site & $16(80)$ \\
\hline Unpleasant/ painful elsewhere & $10(50)$ \\
\hline Sore throat & $4(20)$ \\
\hline Nausea/vomiting & $6(30)$ \\
\hline Dizzy & $5(25)$ \\
\hline Backpain & $1(5)$ \\
\hline Pain in shoulder & $1(5)$ \\
\hline Pain in neck & $2(10)$ \\
\hline Pain in heels & $1(5)$ \\
\hline Pain in mouth & $1(5)$ \\
\hline Headache & $2(10)$ \\
\hline
\end{tabular}


Figure 1 Recruitment of participants

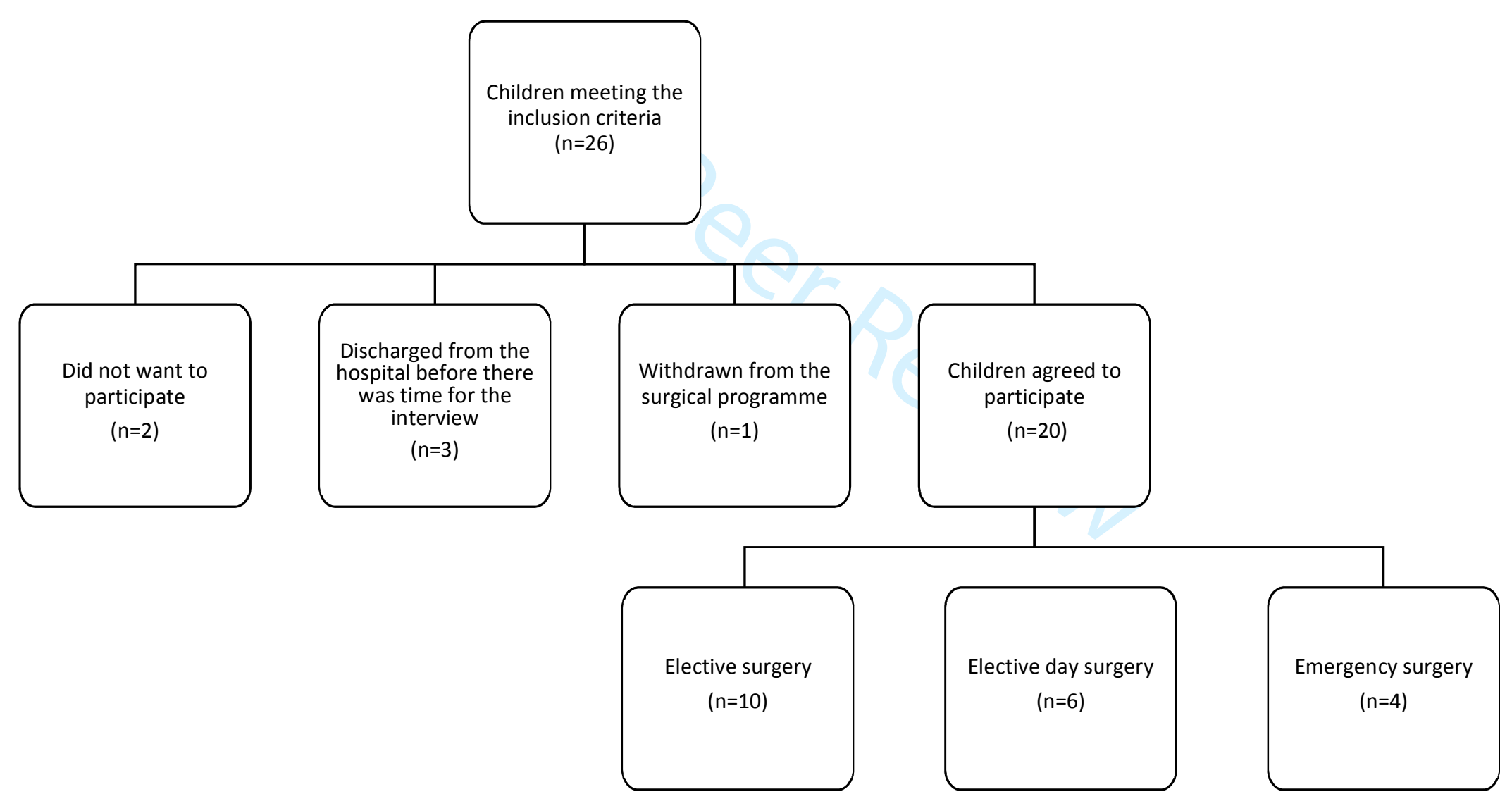


Supplementary File 1

Consolidated criteria for reporting qualitative studies (COREQ): 32-item checklist

\begin{tabular}{|c|c|c|}
\hline No Item & Guide questions/description & \\
\hline \multicolumn{3}{|c|}{$\begin{array}{l}\text { Domain 1: Research team } \\
\text { and reflexivity }\end{array}$} \\
\hline \multicolumn{3}{|l|}{ Personal Characteristics } \\
\hline 1. Interviewer/facilitator & $\begin{array}{l}\text { Which author/s conducted the interview or focus } \\
\text { group? }\end{array}$ & $\begin{array}{l}\text { Author LN and TN conducted the interviews } \\
\text { Author LN, TN and AHS conducted the } \\
\text { content analysis } \\
\text { Described in 3.2.3 procedure }\end{array}$ \\
\hline 2. Credentials & $\begin{array}{l}\text { What were the researcher's credentials? E.g. PhD, } \\
\text { MD }\end{array}$ & $\begin{array}{l}\text { LN, MSc student, intensive care nurse } \\
\text { TN, MSc student, pediatric nurse } \\
\text { AHS, PhD student, pediatric nurse } \\
\text { Described in Essential title page information }\end{array}$ \\
\hline 3. Occupation & What was their occupation at the time of the study? & $\begin{array}{l}\text { Author LN, TN and AHS are clinicians } \\
\text { working at one of the hospitals included in } \\
\text { this study, but not working at any of the } \\
\text { wards. } \\
\text { Described in } 5.6 \text { strengths and limitations } \\
\text { and Essential title page information attached }\end{array}$ \\
\hline 4. Gender & Was the researcher male or female? & $\begin{array}{l}\text { Female, } \\
\text { LN, MSc student, intensive care nurse } \\
\text { TN, MSc student, pediatric nurse } \\
\text { AHS, PhD student, pediatric nurse } \\
\text { Described in Essential title page information }\end{array}$ \\
\hline 5. Experience and training & $\begin{array}{l}\text { What experience or training did the researcher } \\
\text { have? }\end{array}$ & Described in 5.6 strengths and limitations \\
\hline Relationship with particip & & \\
\hline
\end{tabular}




\begin{tabular}{|c|c|c|}
\hline 6. Relationship established & $\begin{array}{l}\text { Was a relationship established prior to study } \\
\text { commencement? }\end{array}$ & $\begin{array}{l}\text { Described in } 3.2 .3 \text { procedure and } 5.6 \\
\text { strengths and limitations }\end{array}$ \\
\hline $\begin{array}{l}\text { 7. Participant knowledge of the } \\
\text { interviewer }\end{array}$ & $\begin{array}{l}\text { What did the participants know about the } \\
\text { researcher? e.g. personal goals, reasons for doing } \\
\text { the research }\end{array}$ & $\begin{array}{l}\text { Nurses, reasons for the research, not part of } \\
\text { the nursing team } \\
\text { Described in } 3.2 .3 \text { procedure and } 5.6 \\
\text { strengths and limitations }\end{array}$ \\
\hline 8. Interviewer characteristics & $\begin{array}{l}\text { What characteristics were reported about the } \\
\text { interviewer/facilitator? e.g. Bias, assumptions, } \\
\text { reasons and interests in the research topic }\end{array}$ & $\begin{array}{l}\text { Education, work experience } \\
\text { Described in } 3.2 .3 \text { procedure and } 5.6 \\
\text { strengths and limitations }\end{array}$ \\
\hline Domain 2: study design & 4 & \\
\hline \multicolumn{3}{|l|}{ Theoretical framework } \\
\hline $\begin{array}{l}\text { 9. Methodological orientation and } \\
\text { Theory }\end{array}$ & $\begin{array}{l}\text { What methodological orientation was stated to } \\
\text { underpin the study? e.g. grounded theory, } \\
\text { discourse analysis, ethnography, phenomenology, } \\
\text { content analysis }\end{array}$ & $\begin{array}{l}\text { Content analysis } \\
\text { Described in } 3.2 \text { Data analysis }\end{array}$ \\
\hline & 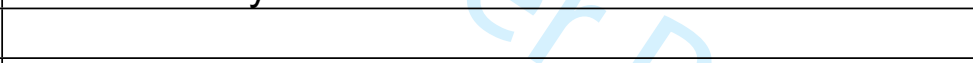 & \\
\hline \multicolumn{3}{|l|}{ Participant selection } \\
\hline 10. Sampling & $\begin{array}{l}\text { How were participants selected? e.g. purposive, } \\
\text { convenience, consecutive, snowball }\end{array}$ & $\begin{array}{l}\text { Convenience } \\
\text { Same participants as in the observational } \\
\text { study, short period of time } \\
\text { Described in } 3.2 \text { Data analysis and } 5.6 \\
\text { strengths and limitations }\end{array}$ \\
\hline 11. Method of approach & $\begin{array}{l}\text { How were participants approached? e.g. face-to- } \\
\text { face, telephone, mail, email }\end{array}$ & $\begin{array}{l}\text { Face-to-face } \\
\text { Described in } 3.2 .3 \text { procedure }\end{array}$ \\
\hline 12. Sample size & How many participants were in the study? & $\begin{array}{l}20, \\
\text { Described in figure } 1\end{array}$ \\
\hline 13. Non-participation & $\begin{array}{l}\text { How many people refused to participate or } \\
\text { dropped out? Reasons? }\end{array}$ & $\begin{array}{l}6, \\
\text { Described in figure } 1\end{array}$ \\
\hline \multicolumn{3}{|l|}{ Setting } \\
\hline 14. Setting of data collection & $\begin{array}{l}\text { Where was the data collected? e.g. home, clinic, } \\
\text { workplace }\end{array}$ & $\begin{array}{l}\text { In the hospital } \\
\text { Described in } 3.2 .3 \text { procedure }\end{array}$ \\
\hline 15. Presence of non-participants & Was anyone else present besides the participants & Two interviewers, and a parent (if they \\
\hline
\end{tabular}




\begin{tabular}{|c|c|c|}
\hline & and researchers? & $\begin{array}{l}\text { wonted) } \\
\text { Described in } 3.2 .3 \text { procedure }\end{array}$ \\
\hline 16. Description of sample & $\begin{array}{l}\text { What are the important characteristics of the } \\
\text { sample? e.g. demographic data, date }\end{array}$ & Described in 3.2. sample and table 1 \\
\hline \multicolumn{3}{|l|}{ Data collection } \\
\hline 17. Interview guide & $\begin{array}{l}\text { Were questions, prompts, guides provided by the } \\
\text { authors? Was it pilot tested? }\end{array}$ & $\begin{array}{l}\text { Interview guide, pilot tests } \\
\text { Described in 3.2.2 data collection tools }\end{array}$ \\
\hline 18. Repeat interviews & $\begin{array}{l}\text { Were repeat interviews carried out? If yes, how } \\
\text { many? }\end{array}$ & No \\
\hline 19. Audio/visual recording & $\begin{array}{l}\text { Did the research use audio or visual recording to } \\
\text { collect the data? }\end{array}$ & $\begin{array}{l}\text { Audio recorded } \\
\text { Described in } 3.2 .3 \text { procedure }\end{array}$ \\
\hline 20. Field notes & $\begin{array}{l}\text { Were field notes made during and/or after the } \\
\text { interview or focus group? }\end{array}$ & $\begin{array}{l}\text { Yes, nurse } 2 \text { wrote notes during the } \\
\text { interview (nurse } 1 \text { interviewed). } \\
\text { Described in 3.2.3 procedure }\end{array}$ \\
\hline 21. Duration & $\begin{array}{l}\text { What was the duration of the interviews or focus } \\
\text { group? }\end{array}$ & $\begin{array}{l}\text { Duration } 12-28 \text { minutes } \\
\text { Described in } 3.2 .3 \text { procedure }\end{array}$ \\
\hline 22. Data saturation & Was data saturation discussed? & $\begin{array}{l}\text { No, because of limited time of collection the } \\
\text { number were convenient }\end{array}$ \\
\hline 23. Transcripts returned & $\begin{array}{l}\text { Were transcripts returned to participants for } \\
\text { comment and/or correction? }\end{array}$ & No \\
\hline \multicolumn{3}{|l|}{$\begin{array}{l}\text { Domain 3: analysis and } \\
\text { findings }\end{array}$} \\
\hline \multicolumn{3}{|l|}{ Data analysis } \\
\hline 24. Number of data coders & How many data coders coded the data? & $\begin{array}{l}\text { Three; LN, TN and AHS } \\
\text { Described in } 3.4 \text { data analysis }\end{array}$ \\
\hline 25. Description of the coding tree & $\begin{array}{l}\text { Did authors provide a description of the coding } \\
\text { tree? }\end{array}$ & $\begin{array}{l}\text { All did the individual coding first } \\
\text { Described in } 3.4 \text { data analysis }\end{array}$ \\
\hline 26. Derivation of themes & Were themes identified in advance or derived from & No, they were derived from the data \\
\hline
\end{tabular}




\begin{tabular}{|l|l|l|}
\hline 27. Software & the data? & Described in 4 results \\
\hline 28. Participant checking & $\begin{array}{l}\text { What software, if applicable, was used to manage } \\
\text { the data? }\end{array}$ & $\begin{array}{l}\text { NVIVO } \\
\text { Described in 3.4 data analysis }\end{array}$ \\
\hline Reporting & Did participants provide feedback on the findings? & No \\
\hline 29. Quotations presented & $\begin{array}{l}\text { Were participant quotations presented to illustrate } \\
\text { the themes / findings? Was each quotation } \\
\text { identified? e.g. participant number }\end{array}$ & $\begin{array}{l}\text { Yes, and yes, (e.g. case 12, 11 years) } \\
\text { Described in 4 Results }\end{array}$ \\
\hline 30. Data and findings consistent & $\begin{array}{l}\text { Was there consistency between the data } \\
\text { presented and the findings? }\end{array}$ & $\begin{array}{l}\text { Yes } \\
\text { Described in 4 Results }\end{array}$ \\
\hline 31. Clarity of major themes & $\begin{array}{l}\text { Were major themes clearly presented in the } \\
\text { findings? }\end{array}$ & $\begin{array}{l}\text { Yes } \\
\text { Described in 4 Results }\end{array}$ \\
\hline 32. Clarity of minor themes & $\begin{array}{l}\text { Is there a description of diverse cases or } \\
\text { discussion of minor themes? }\end{array}$ & $\begin{array}{l}\text { No description of diverse cases, but } \\
\text { discussion of minor themes is described in 4 } \\
\text { Results }\end{array}$ \\
\hline
\end{tabular}

